Укусы людей собаками: общая характеристика

\author{
М.Т. Макенов ${ }^{\text {a*, O.А. Михайлова }}{ }^{6}$ \\ а Омский научно-исследовательский институт \\ природно-очаговых инфекиий Роспотребнадзора, \\ Россия 644080, Омск, пр. Мира, 7 \\ ${ }^{6}$ Центр гигиень и эпидемиологии по Омской области, \\ Россия 644116, Омск, ул. Северная 27-я, $42 a$
}

Received 27.12.2011, received in revised form 06.03.2013, accepted 22.03.2013

В статье проведён анализ обращуений жителей г. Омска за медицинской помощуью с травмами от укусов собак в период 2006-2010 г2. на основе материалов, предоставленных ФБУЗ «Центр гигиены и эпидемиологии по Омской области». Всего за указанный период в г. Омске зарегистрировано 11849 укусов людей собаками. Среднее количество составило 2901,3 укуса в год, что соответствует 256,9 случая на 100000 человек. По мнению пострадавщих, в $99 \%$ случаев укус наносили владельческие собаки, причём в 66 \% случаев укус наносили известные респонденту животные, укусы бродячих собак составили 0,36 \%. Выявлена выраженная сезонная зависимость: максимальное количество обращений за медицинской помощью с травмами от укусов собак приходится на летние месяцы - с мая по август включительно, минимальное - в зимний период, с ноября по февраль. Дети страдают от укусов собак чащее, чем взрослье, при этом сравнительно высок процент укусов в область головы и шеи - 19-44\%. Взрослых людей чащче всего кусают за руки или за ноги - 87 \% от всех укусов. Женщин кусают реже, чем мужчин, - 217,6 и 304,0 укусов на 100000 человек соответственно.

Ключевые слова: собаки, укусы, агрессия, бродячие животные.

\section{Введение}

Собаки являются одними из самых предпочитаемых домашних питомцев в России (Шмерлина, 2007). Численность владельческих собак в США оценивалась примерно в 5258 млн особей (American Veterinary..., 1997), в Австралии - около 3,9 млн особей (McHarg et al., 1995), численность собак во всём мире, по оценкам супругов Коппингер, составляет примерно 400 млн (Coppinger, Coppinger, 2002). Собак используют на службе, содержат в питомниках, квартирах, с ними играют, их тренируют, воспитывают, поддерживают у некоторых пород бойцовские, сторожевые

(c) Siberian Federal University. All rights reserved

* Corresponding author E-mail address: makenovm@mail.ru 
качества. Такое тесное взаимодействие двух видов неизбежно влечёт за собой возникновение различных конфликтных ситуаций, недоразумений и несчастных случаев, которые находят свои проявления в агрессии и нападении собак на человека. По некоторым оценкам, 1 собака из 20 хотя бы раз за свою жизнь кусала человека (Griego, 1995), а при определённых обстоятельствах любая собака может нанести вред здоровью человека (Presutti, 2001). Нападение может ограничиться лаем, рычанием и демонстрацией угрозы, а может привести и к серьёзным травмам, которые могут стать причиной смерти человека (Sacks et al., 2000; Ozanne-Smith et al., 2001). Кроме того, агрессия собак может быть причиной серьёзных психологических проблем, в особенности при нападении на детей и подростков (Schalamon et al., 2006).

Причины нападения собаки на человека разнообразны, они во многом зависят от численности собак, условий их содержания, особенностей отношения людей к животным и т.д. Несмотря на обширные исследования данной проблематики, проведённые зарубежными авторами, тема нападения собак на людей в российских городах остаётся недостаточно изученной.

В этой связи цель данной статьи была сформулирована следующим образом: охарактеризовать укусы собаками людей на большом статистическом материале, собранном в крупном российском городе.

\section{Материалы и методы}

Исследование проводили в г. Омске в 2010-2011 гг. В работе были использованы материалы по укусам жителей г. Омска с июня 2006 по июнь 2010 г., предоставленные Федеральным бюджетным учреждением здравоохранения «Центр гигиены и эпидемиологии по Омской области». Полученная база данных включала в себя все случаи обращений горожан в учреждения здравоохранения г. Омска с просьбами оказать медицинскую помощь после укусов животных. В базе фиксировали пол, возраст и место жительства пострадавшего, дату укуса, характеристику укусившего животного, локализацию укуса.

При изучении частоты укусов по сезонам применяли дисперсионный анализ, где в качестве фактора использовали время года. При анализе временного ряда применяли мультипликативную модель:

$$
\mathrm{x}_{\mathrm{t}}=\operatorname{tr}_{\mathrm{t}} \cdot \mathrm{s}_{\mathrm{t}} \cdot \varepsilon_{\mathrm{t}}
$$

где $\operatorname{tr}_{\mathrm{t}}$ - тренд; $\mathrm{s}_{\mathrm{t}}$ - сезонная компонента; $\varepsilon_{\mathrm{t}}-$ случайная компонента.

Для выделения тренда была произведена сезонная декомпозиция временного ряда по мультипликативной модели с использованием скользящего среднего (период сезонности - 12 месяцев) и последующим регрессионным анализом.

Для анализа половозрастной структуры пострадавших были использованы сведения территориального органа Федеральной службы государственной статистики по Омской области о численности мужского и женского населения г. Омска по возрастным группам за исследуемый период. При сравнении мужское и женское население города рассматривали как отдельные выборки. Определяли долю лиц, пострадавших от укусов собак, затем с помощью $\varphi$-критерия Фишера (угловое преобразование) оценивали достоверность различий между процентными долями двух выборок. Аналогичным образом производили сравнение по возрастным группам.

Для обработки и анализа данных были использованы пакеты программ Microsoft Excel и SPSS Statistics. 


\section{Результаты}

\section{Статус собак}

Всех пострадавших просили определить статус укусивших их собак по отношению к человеку и предлагали следующие варианты ответа: животное бродячее; животное домашнее известное; животное домашнее неизвестное. Статус «бродячее» указывали при укусе бесхозяйной собаки, статус «домашнее известное» - если пострадавший знал собаку, её владельца или сам был её хозяином, статус «домашнее неизвестное» - если респондент считал, что его укусила владельческая собака, но он не знал, где она живёт и кто её владелец.

В связи с тем что первичные материалы за 2006 и 2010 гг. неполные, для расчёта среднегодовых значений были использованы данные с 2007 по 2009 гг. включительно (табл. 1). Всего за указанный период зарегистрировано 11849 укусов людей собаками. Среднее количество укусов составило 2901,3 случая в год, что соответствует 256,9 укусу на 100000 человек.
При анализе информации о животных, нанёсших укус, было выявлено, что в большинстве случаев, 99,6 \%, укусы наносили собаки, имеющие хозяина («домашние известные» и «домашние неизвестные»); «бродячие», по мнению респондентов, кусали в $0,3 \%$ случаев (табл. 1 ).

\section{Сезонность укусов}

При изучении сезонной динамики агрессивного поведения собак по отношению к человеку мы предполагали наличие зависимости количества нанесённых укусов от времени года. Для проверки этой гипотезы полученные данные были разделены на четыре сезона: зима, весна, лето, осень (табл. 2). Дисперсионный анализ подтвердил наличие зависимости количества укусов от сезона $(\mathrm{F}=35,22 ; \mathrm{p}<0,001)$.

Для того чтобы понять характер зависимости, данные по укусам были представлены в виде временного ряда (рис. 1).

Таблица 1. Статус укусивших собак, по мнению пострадавших (n - абсолютное количество; \% - от общего числа укусов за год)

\begin{tabular}{|c|c|c|c|c|c|c|c|c|}
\hline \multirow{3}{*}{ Год } & \multicolumn{8}{|c|}{ Количество укусов } \\
\hline & \multirow[t]{2}{*}{ Общее } & \multicolumn{2}{|c|}{$\begin{array}{c}\text { Домашними } \\
\text { известными } \\
\text { собаками }\end{array}$} & \multicolumn{2}{|c|}{$\begin{array}{c}\text { Домашними } \\
\text { неизвестными } \\
\text { собаками }\end{array}$} & \multicolumn{2}{|c|}{$\begin{array}{c}\text { Бродячими } \\
\text { собаками }\end{array}$} & \multirow[t]{2}{*}{$\begin{array}{c}\text { Нет } \\
\text { данных }\end{array}$} \\
\hline & & $\mathrm{n}$ & $\%$ & $\mathrm{n}$ & $\%$ & $\mathrm{n}$ & $\%$ & \\
\hline \multicolumn{9}{|l|}{2006} \\
\hline 2007 & 3233 & 2174 & 67,2 & 1054 & 32,6 & 4 & 0,1 & 1 \\
\hline 2008 & 2762 & 1977 & 71,6 & 781 & 28,3 & 3 & 0,1 & 1 \\
\hline 2009 & 2709 & 1905 & 70,3 & 798 & 29,5 & 3 & 0,1 & 3 \\
\hline $\begin{array}{l}2010 \\
\text { (янв.-июнь) }\end{array}$ & 1227 & 766 & 62,4 & 459 & 37,4 & 1 & 0,1 & 1 \\
\hline$\Sigma$ & 11849 & 8174 & 69,0 & 3622 & 30,6 & 41 & 0,3 & 11 \\
\hline $\mathrm{m} \pm \mathrm{SD}^{*}$ & $2901,3 \pm 288,5$ & \multicolumn{2}{|c|}{$2018,7 \pm 139,3$} & \multicolumn{2}{|c|}{$877,7 \pm 152,9$} & \multicolumn{2}{|c|}{$3,3 \pm 0,6$} & \\
\hline \multicolumn{9}{|l|}{ Ср. кол-во* } \\
\hline 100 тыс.чел. & 256,9 & & & & & & & \\
\hline
\end{tabular}

*- средние значения рассчитаны за период 2007-2009 гг. 
Таблица 2. Распределение количества укусов в зависимости от времени года (N - количество изученных месяцев в сезоне)

\begin{tabular}{cccccc}
\hline Время года & $\mathrm{N}$ & Среднее & $\begin{array}{c}\text { Стандартное } \\
\text { отклонение }\end{array}$ & Минимум & Максимум \\
\hline Зима & 12 & 143,3 & 34,9 & 109 & 223 \\
Весна & 12 & 272,9 & 83,8 & 161 & 408 \\
Лето & 13 & 343,8 & 30,3 & 278 & 383 \\
Осень & 12 & 196,4 & 43,6 & 114 & 255 \\
Итого & 49 & 241,2 & 92,5 & 109 & 408 \\
\hline
\end{tabular}

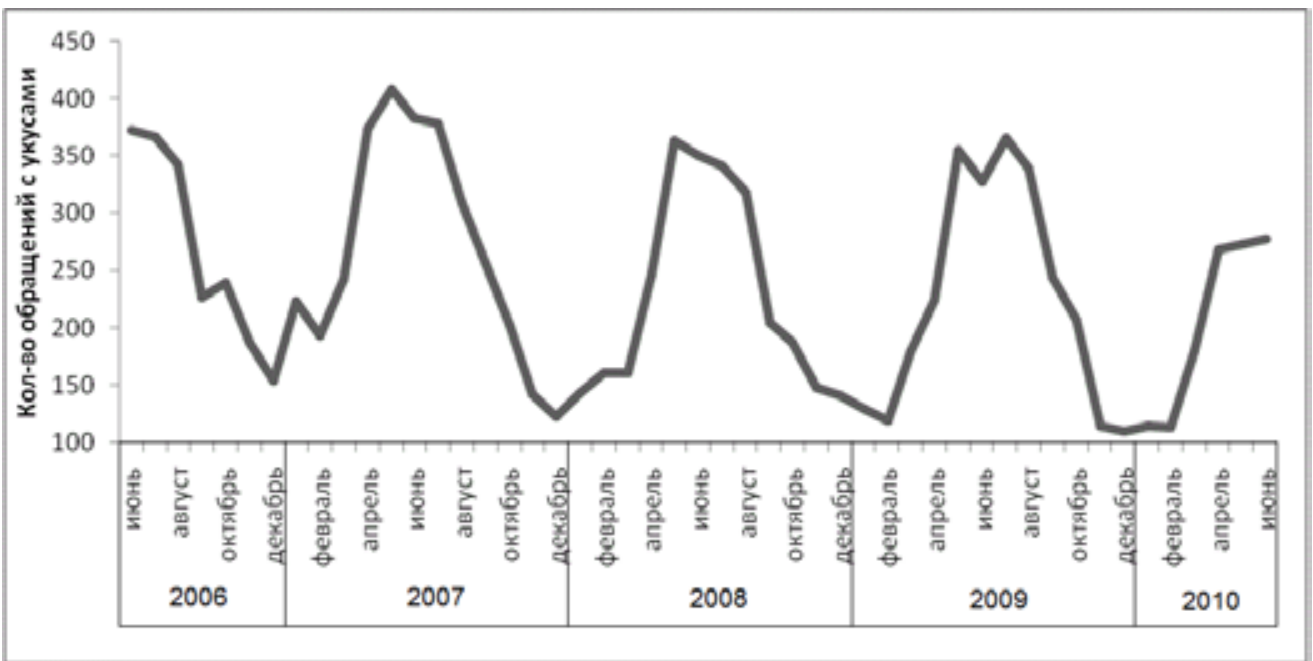

Рис. 1. Количество обращений жителей г. Омска за медицинской помощью с травмами от укусов собак, июнь 2006 г. - июнь 2010 г.

На графике можно выделить чёткую сезонную периодичность и незначительный отрицательный тренд. В течение года максимальное количество обращений за медицинской помощью с травмами от укусов собак приходится на летние месяцы - с мая по август включительно, минимальное - в зимний период, с ноября по февраль.

Наряду с сезонной компонентой интерес представляет и тренд. Анализ полученного после устранения сезонной компоненты ряда показал наличие отрицательного тренда, который был аппроксимирован линейной моделью (рис. 2):

$$
y=284,01-1,76 x ; R^{2}=0,40
$$

коэффициент детерминации и коэффициенты уравнения регрессии статистически значимы $(\mathrm{p}<0,001)$.

Анализ остатков регрессионной модели показал наличие выбросов - значения количества укусов в январе и апреле 2007 г. Выбросы, возможно, объясняются тем, что в предложенной модели временного ряда, помимо тренда $\left(\operatorname{tr}_{t}\right)$ и сезонной составляющей $\left(\mathrm{s}_{t}\right)$, присутствует также циклическая компонента $\left(\mathrm{c}_{\mathrm{t}}\right)$ - длительные периоды относительного подъёма и спада. Однако для оценки 


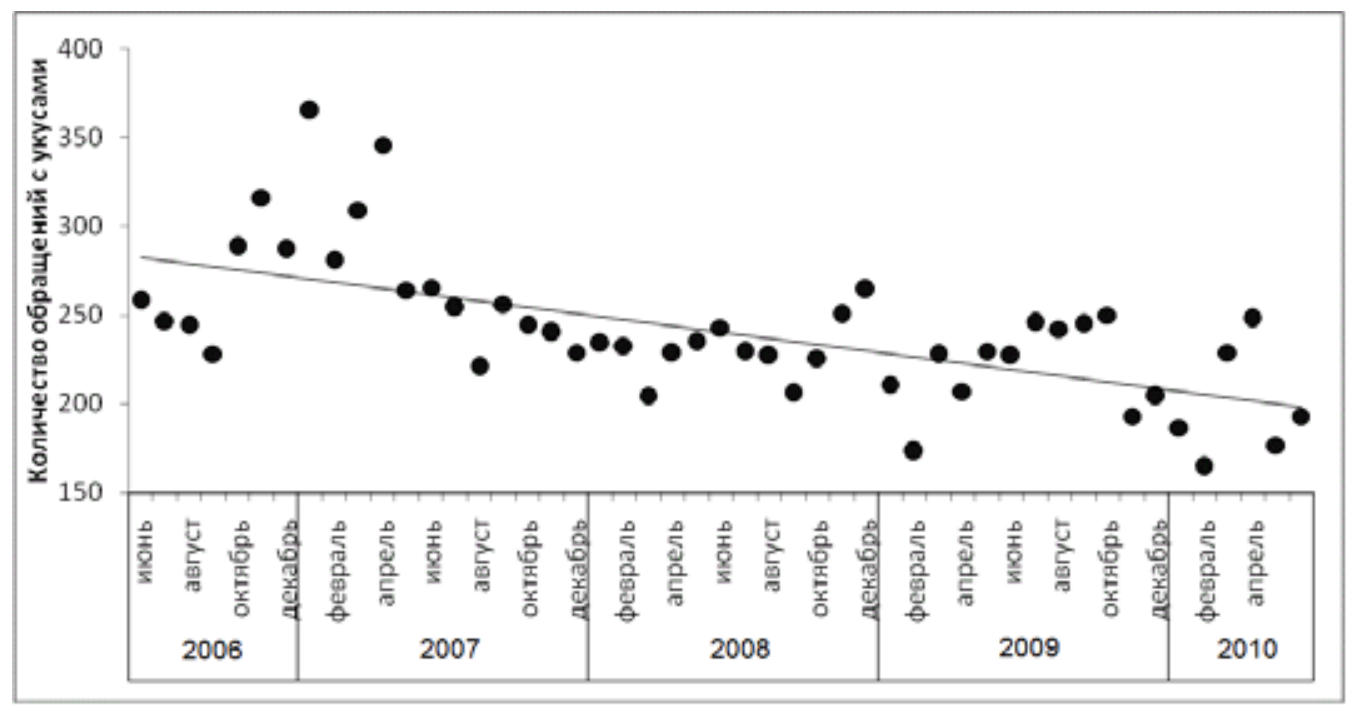

Рис. 2. Обращения жителей г. Омска за медицинской помощью с травмами от укусов собак, июнь 2006 г. июнь 2010 г., после сезонной декомпозиции временного ряда (с линией тренда у $=284,01-1,76 x)$

циклической компоненты необходимы долговременные наблюдения, в нашем распоряжении были данные лишь за четыре года, что не позволяет охарактеризовать циклические колебания.

\section{Половозрастная структура пострадавших}

Было установлено, что мужчин собаки кусали чаще, чем женщин: в среднем за три года 304,0 и 217,6 укуса на 100000 человек соответственно $(\varphi=9,0 ; p<0,01)$. При рассмотрении по возрастным группам (рис. 3) выявлено, что собаки кусали мальчиков достоверно чаще, чем девочек, в возрасте от 5 до 15 лет $(\varphi \geq 2,5 ; p<0,01)$ и мужчин в возрасте от 20 до $40(\varphi \geq 2,7 ; p<0,01)$ и от 70 до 75 лет $(\varphi=1,7$; $\mathrm{p}<0,05)$ чаще, чем женщин того же возраста. В остальных возрастных группах значимых различий между укусами, наносимыми мужчинам и женщинам, не наблюдалось. В целом по возрастам чаще всего жертвами укусов собак становились дети и молодые люди в возрасте от 5 до 19 лет (рис. 3).

\section{Локализация укусов}

При рассмотрении локализации укусов было установлено, что в большинстве случаев собаки кусали за конечности - 87 \% (рис. 4). Реже всего укусы приходились в область туловища, шеи и головы, причём наиболее опасные по своим последствиям укусы в голову и шею отмечались в среднем в 8,3 \% случаев.

При изучении локализации укуса в зависимости от пола пострадавшего было выявлено, что в среднем, по данным 2007-2009 гг., женщин кусали за ноги чаще, чем мужчин, а мужчин за руки кусали чаще, чем женщин $(\mathrm{p}<0,05)$.

С возрастом пострадавших локализация укусов также претерпевает некоторые изменения (рис. 4). Для детей младше 10 лет характерен сравнительно высокий процент укусов в голову - от 44 до $19 \%$ и в корпус тела $-8-10 \%$, за ноги детей кусали относительно редко - 16-40\%. У людей старше 65 лет возрастает доля укусов за руки - 50 \% и более. 


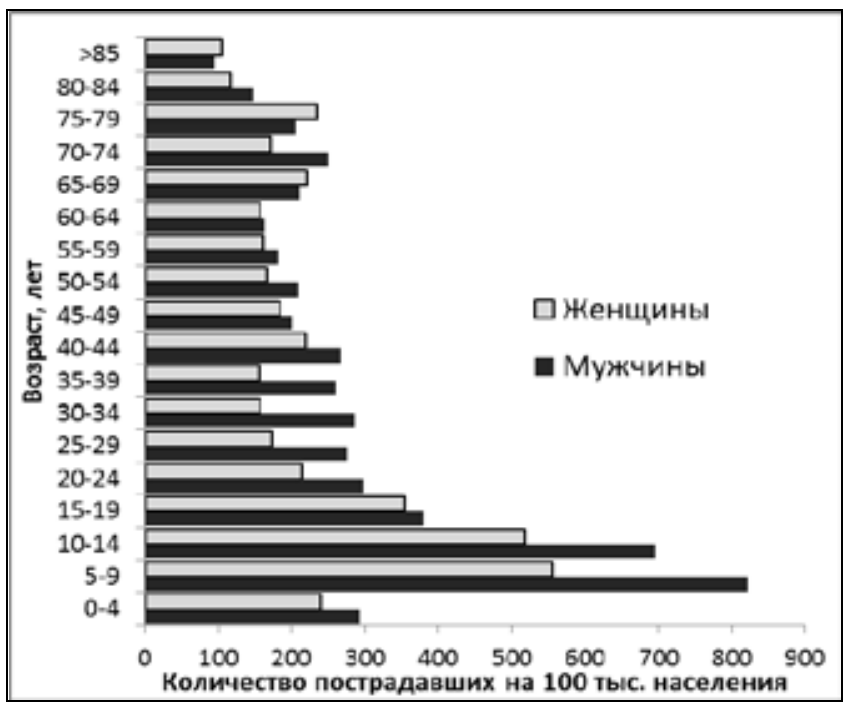

Рис. 3. Половозрастное распределение пострадавших от укусов собак, средние значения за 2007-2009 гг.

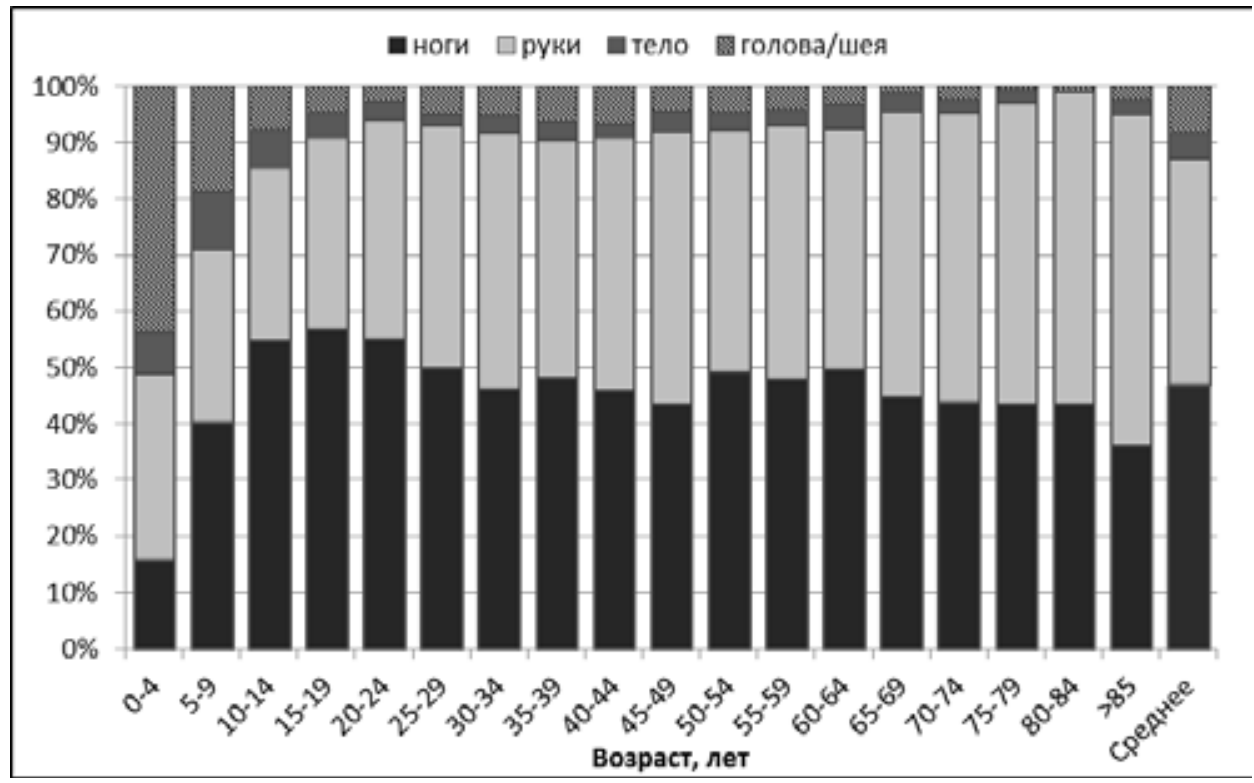

Рис. 4. Локализация укусов в зависимости от возраста пострадавших

\section{Обсуждение}

Полученные в ходе исследования значения количества укусов собаками в г. Омске являются сравнительно высокими - в среднем 2901,3 укуса в год (256,9 случаев на 100000 человек). Среди отечественных публикаций обстоятельных исследований, посвящённых изучению укусов собак и их причин, нам найти не удалось, поэтому мы сравнили полученные данные только с результатами зарубежных авторов (табл. 3).

Как видно, наиболее близкое количество укусов было зарегистрировано в г. Питтсбург в 1993 г. - 214 случаев на 100000 человек 
Таблица 3. Данные о количестве укусов людей собаками в разных городах

\begin{tabular}{l|c|c|c|c}
\hline Город (страна) & $\begin{array}{c}\text { Численность } \\
\text { населения, чел. }\end{array}$ & $\begin{array}{c}\text { Количество укусов } \\
\text { собак на } 100000 \text { чел. }\end{array}$ & $\begin{array}{c}\text { Период } \\
\text { исследования }\end{array}$ & Авторы \\
\hline Гуелф (Канада) & 115 тыс. & 160 & $1986-1987$ гг. & $\begin{array}{c}\text { Szpakowski et al., } \\
1989\end{array}$ \\
Малага (Испания) & 560 тыс. & 150 & $1984-1988$ гг. & $\begin{array}{c}\text { Rufino Gonzales, } \\
1990\end{array}$ \\
Питтсбург (США) & 313 тыс. & 214 & 1993 г. & Chang et al., 1997 \\
Болонья (Италия) & 380 тыс. & $589 *$ & $2000-2002$ гг. & Ostanello et al., \\
Белград (Сербия) & 1213 тыс. & 58 & 2005 \\
\hline
\end{tabular}

* - Скорректированное число, которое было рассчитано после учёта укусов людей, не обратившихся за медицинской помощью.

(Chang et al., 1997). В городах Гуелф, Малага и Белград инциденты с укусами собак происходили значительно реже - примерно 150160 случаев на 100000 населения (Szpakowski et al., 1989; Rufino Gonzales, 1990; Vucinic, 2008).

Количество укусов собак зависит от многих причин, среди которых: численность и структура населения города, численность популяции собак, особенности городской застройки, условия содержания собак и др. На данном этапе исследования однозначно интерпретировать столь высокие значения числа укусов, полученных для г. Омска, не представляется возможным, поскольку необходимо изучить ситуационный контекст, охарактеризовать особенности отношения людей к собакам и т.д.

Один из наиболее значимых результатов, полученных при анализе данных, заключается в том, что бо́льшая часть укусов была нанесена, по мнению пострадавших, владельческими собаками. Причём в 69 \% случаев пострадавшие на вопрос о типе укусившей собаки выбирали ответ «домашняя известная», а это значит, что они либо сами были владельцами этой собаки, либо состояли в родственных, дружеских, соседских отношениях с хозяином собаки. В остальных 30,6 \% случаев пострадавшие определяли собак как «домашние неизвестные», данный вариант ответа выбирали, если укус наносили животные, владельцев которых пострадавший не знал. Такие нападения могли возникнуть при недостаточном контроле хозяина за собакой во время прогулки или при так называемом свободном выгуле, когда собака может свободно, без сопровождения владельца, покидать территорию домохозяйства.

Приведённая статистика указывает на то, что многие владельцы собак не обладают достаточными знаниями о том, каким образом необходимо выстраивать отношения со своим питомцем, как его воспитывать, дрессировать, выгуливать, содержать. К аналогичным выводам пришли и зарубежные исследователи.

Так, в работе коллектива авторов, изучавших укусы собак в 1972-1973 гг. в СентЛуисе, было установлено, что в 5,9 \% случаев жертвами укусов собак становились владельцы или члены их семьи (Beck et al., 1975). В $64,8 \%$ из всех рассмотренных авторами инцидентов пострадавшие непосредственно 
перед укусом взаимодействовали с собакой, её хозяином или собственностью хозяина. В 25,4 \% случаев пострадавшие перед укусом взаимодействовали с собакой. Чаще всего это были игры с собакой, ласка собаки, разнимание дерущихся животных, преднамеренная провокация, а также пострадавшие наступали на хвост или лапу собаке, беспокоили её во время еды, пытались взять на руки, на поводок и др. (Beck et al.,1975).

По данным Вайс с соавторами (Weiss et al., 1998), в США 58 \% всех укусов собак люди получали, находясь у себя дома. В исследовании укусов детей до 17 лет в г. Грац (Австрия) было выявлено, что 73 \% всех укусов наносили собаки, которых пострадавший знал: в 24 \% случаев собака принадлежала члену семьи пострадавшего, в 14 - родственнику, в 20 - другу, в 15 - соседям и лишь в 15 - кусала неизвестная собака (Schalamon et al., 2006).

Следует отметить, что результаты зарубежных исследований могут значительно отличаться от выявленных нами общих закономерностей в связи с существенными культурными различиями, отличиями в особенностях содержания собак, отношения к ним и т.д. В проведённом нами исследовании было установлено, что бесхозяйные собаки кусали людей, по мнению пострадавших, лишь в 0,36 \% случаев - в среднем 3,3 укуса в год. Для сравнения, по данным зарубежных исследователей, доля укусов, нанесённых бесхозяйными собаками, значительно выше и составляет 10-14 \%, что составляет около 200-350 случаев в год (Parrish et al., 1959; Beck et al., 1975). В Белграде (2003-2006 гг.) количество укусов, нанесённых бродячими собаками (stray dogs), достоверно превышало количество укусов владельческих собак - 1507,5 и 832,8 укуса в год соответственно, что составляло 95,6 и 52,8 случая на 100000 человек (Vucinic, 2008).
Столь незначительные цифры, полученные нами для г. Омска, могут объясняться двумя причинами: особенностями поведения бесхозяйных собак по отношению к человеку и снижением численностью популяции бесхозяйных собак в последние годы. Собственные наблюдения показывают, что бесхозяйные собаки боятся человека, стараются избегать непосредственного контакта и выдерживают дистанцию. Агрессивное поведение они проявляют в виде лая, рычания и демонстрации угрозы, порой с выпадами в сторону человека, однако активных оборонительных действий человека (резкий взмах рукой, сумкой) достаточно, чтобы предотвратить нападение и укус.

Помимо поведенческих особенностей на количество укусов также влияет и численность бесхозяйных собак. Последние учёты численности популяции собак-парий в г. Омске проводили в 2005 г. (Макенов, Кассал, 2006), на тот момент совокупное население бесхозяйных собак и собак полувольного содержания составляло около 14 тыс. особей. Однако за 2006-2010 гг., по данным Департамента городского хозяйства Администрации г. Омска, специальными службами было отловлено 54487 бродячих собак, причём ежегодно наблюдалось снижение общего количества отловленных собак (рис. 5). Эти данные, а также результаты собственных учётов на типовых площадках указывают на снижение численности популяции собак-парий и их перераспределение на территории города. Это, возможно, и является одной из причин столь незначительного количества укусов, нанесённых бесхозяйными собаками.

Выраженная сезонность укусов, обнаруженная при анализе временного ряда, имеет несколько возможных причин. В холодное время года вне дома ввиду низких температур рано темнеет, поэтому владельцы со- 


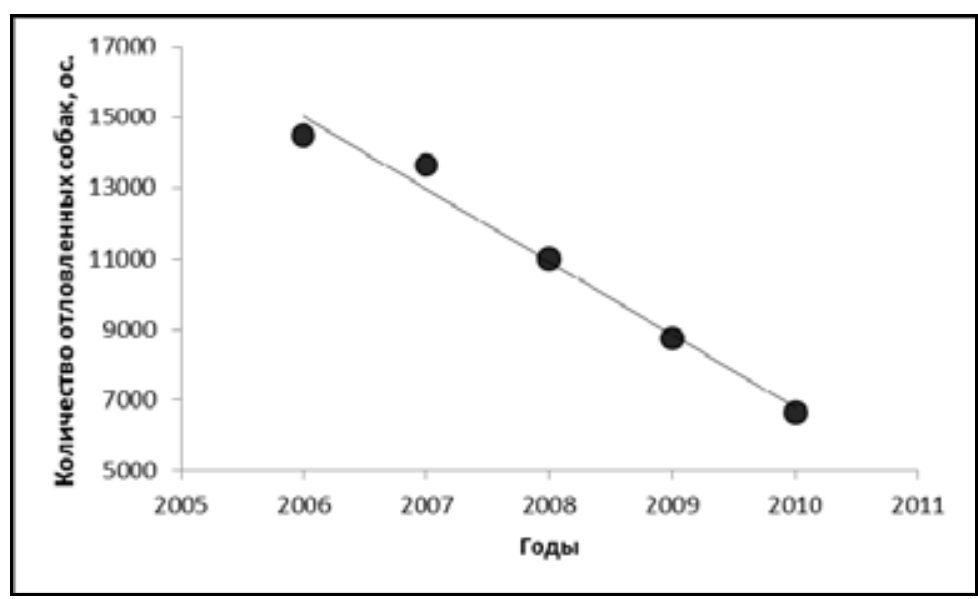

Рис. 5. Количество собак, отловленных коммунальными службами Департамента городского хозяйства г. Омска с 2006 по 2010 гг. (с линией тренда у = 17077,7 - 2060,1x)

бак стараются выгуливать своих питомцев непродолжительное время. Это уменьшает вероятность контакта собак с прохожими, посторонними людьми. Кроме того, в это время года собакам сложно нанести скольконибудь значимый укус, так как люди используют плотную зимнюю одежду, которую труднее прокусить и нанести травму. Нападения собак, возможно, происходят с такой же частотой, что и летом, но они не приводят к травме, и люди не обращаются за медицинской помощью. Летом, напротив, в связи с сезоном отпусков, школьными каникулами очень много людей проводят время на прогулках, в том числе и владельцы собак со своими питомцами, люди носят лёгкую одежду - всё это увеличивает вероятность нанесения укуса.

Литературные данные о сезонном характере укусов разнятся. Так, в Болонье (Италия), Граце (Австрия), Белграде (Сербия), а также в Канаде собаки достоверно чаще кусали людей в теплые месяцы: с мая по август, с пиком в августе (Ostanello et al., 2005; Schalomon et al., 2006; Vucinic et al., 2008). Исследования в г. Эль-Пасо (США) сезонной зависимости не выявили (Patrick, O'Rourke, 1998). Вайс с соавторами (Weiss et al., 1998), изучая инциденты с укусами собак в США, выявил незначительную тенденцию к сезонности укусов с пиком в летние месяцы, однако, несмотря на то что большинство укусов было зарегистрировано в южных штатах, скорректированные популяционные оценки по штатам были примерно равны и не имели достоверных отличий.

При изучении полового соотношения пострадавших в большинстве работ было установлено, что мужчин собаки кусают чаще (Szpakowski et al., 1989; Sacks et al., 1996; Patrick, O'Rourke, 1998; Ostanello et al., 2005; MacBean et al., 2007). В настоящем исследовании была выявлена такая же закономерность, определены возрастные группы, в которых наблюдается достоверная разница.

Причиной того, что в возрастной группе младше 15 лет мальчиков собаки кусают чаще, чем девочек, вероятнее всего, является разница в их поведении. Мальчики в этом возрасте чаще девочек играют в игры, которые могут раздражать собак и провоцировать их агрессию: катание на велосипеде, роликах, бег, игры в мяч, игры в гаражных коопера- 
тивах, складах, огороженных территориях предприятий. Кроме того, мальчики могут специально дразнить собак или навязывать своим питомцам грубые игры (садиться верхом, тянуть за хвост и т.д.). Мужчин в возрасте от 20 до 40 лет собаки кусают чаще, чем женщин, вероятно, потому, что мужчины более жёсткие и грубые по отношению к своим питомцам, чаще их наказывают.

Анализ данных по возрастным группам показал, что собаки чаще всего кусают детей и молодых людей в возрасте от 5 до 19 лет. Аналогичные результаты были получены в большинстве исследований зарубежных авторов, проведённых в разных городах и странах. В изученных работах различия наблюдаются лишь в возрастной периодизации, но, несмотря на это, чётко просматривается общая закономерность - детей и подростков собаки кусали чаще, чем взрослых (Sacks et al., 1996; Ostanello et al., 2005; MacBean et al., 2007). По данным Вайс с соавторами (Weiss et al., 1998), в США чаще всего кусают детей до 9 лет, самая высокая частота была отмечена у мальчиков от 5 до 9 лет - 607 укусов на 100000 человек. Сходные данные были получены Саксом с соавторами (Sacks et al., 1996) - количество укусов в США составило для взрослых (старше 18 лет) 200 на 100000 населения, а для детей (до 14 лет) - 640 на 100000 человек.

Основные причины такого преобладания укусов детей над укусами взрослых, по мнению Розенберга с соавторами (Rosenberg, 1995), могут заключаться в следующем: невысокий рост детей делает их менее страшными для собак, а незрелость и отсутствие здравого смысла иногда заставляют детей действовать таким образом, что животное воспринимает это как угрозу или агрессию.

Выявленные особенности анатомической локализации укусов также имеют очевидные причины. Область ног хорошо подходит для нанесения укуса, так как соответствует по высоте росту собаки и удобна для захвата зубами. В область рук укусы наносятся, как правило, в тех случаях, когда пострадавший тянет руки к собаке (пытается погладить, покормить, наказать, провести гигиеническую или медицинскую процедуру) или же защищается от нападения собаки, закрываясь рукой. По мнению Е.С. Березиной и соавторов (2010), в область головы и шеи люди получают укусы преимущественно от владельческих собак, так как не ожидают от них нападения и не успевают закрыться рукой.

По литературным данным, локализация укусов собак в определённой степени варьирует. Однако можно выделить две общих закономерности, отмеченные во многих исследованиях: собаки в большинстве своём наносят один укус (Szpakowski et al., 1989; Patrick et al., 1998; Schalomon et al., 2006), детей чаще всего кусают в голову, лицо или шею (Szpakowski et al., 1989; Gershman et al., 1994; Weiss et al., 1998; Ostanello et al., 2005; Schalomon et al., 2006). В целом по всем возрастным группам большая часть укусов приходится на руки - 26-48 \% и на ноги - 18-36 \%, а в корпус тела кусают редко - 4-10 \% всех случаев (Szpakowski et al., 1989; Gershman et al., 1994; Patrick et al., 1998; Ostanello et al., 2005; Schalomon et al., 2006). Приведённые значения хорошо соотносятся с полученными нами данными.

\section{Заключение}

В г. Омске зарегистрировано сравнительно высокое количество укусов человека собаками - в среднем 2901,3 случая в год, что соответствует 256,9 укуса на 100000 населения. Большинство собак, нанёсших укус, пострадавшие знали: 69 \% было нанесено домашними известными собаками и 30,6 \% - домаш- 
ними неизвестными, бродячие собаки кусали редко - в $0,36 \%$ случая. В весенне-летний период за медицинской помощью с травмами от укусов собак люди обращаются достоверно чаще, чем зимой и осенью. Дети страдают от укусов собак чаще, чем взрослые, при этом сравнительно высок процент укусов в область головы и шеи. Взрослых людей чаще всего кусают за руки или за ноги. Женщин собаки кусают реже, чем мужчин.

\section{Список литературы}

1. Березина Е.С., Сидоров Г.Н., Полещук Е.М., Сидорова Д.Г. (2010) Бешенство собак в России во второй половине XX - начале XXI века. Российский ветеринарный журнал. Мелкие домашние и дикие животные. №3: 2-6.

2. Макенов М.Т., Кассал Б.Ю. (2006) Исследование популяции собак-парий г. Омска. В: Проблемы исследований домашней собаки. Материалы совещания. Отв.ред. А.В. Шубкина, ИПЭЭ им. А.Н. Северцова РАН, Москва, с.123-138.

3. Шмерлина И. (2007) Собаки и их владельцы. В: Социальная реальность. № 10, с.35.

4. American Veterinary Medical Association. (1997) US pet ownership and demographics sourcebook. Schaumburg, Ill: AVMA Center for Information Management, p. 1-105.

5. Beck A.M., Loring H., Lockwood R. (1975) The ecology of dog bite injury in St. Louis, Missouri. Public Health Reports. 90 (3): 262-267.

6. Chang Y.F., MacMahon J.E., Hennon D.L., LaPorte R.E., Coben J.H. (1997) Dog bite incidence in the city of Pittsburg: a capture-recapture approach. American Journal of Public Health. 87 (10): 1703-1705.

7. Coppinger R., Coppinger L. (2002) Dogs: A new understanding of canine origin, behavior, and evolution. Chicago: University of Chicago Press, $352 \mathrm{p}$.

8. Gershman K.A., Sacks J.J., Wright J.C. (1994) Which dog bite? A case-control study of risk factors. Pediatrics. 93(6): 913-917.

9. Griego R., Rosen T., Orengo I., Wolf J. (1995) Dog, cat, and human bites: A review. J. Am. Acad. Dermatol. 33: 1019-29.

10. MacBean C.E., Taylor D. McD., Ashby K. (2007) Animal and human bite injuries in Victoria, 1998-2004. Medical Journal of Australia. 186 (1): 38-40.

11. McHarg M., Baldock C., Headey B., et al. (1995) National people and pets survey. Melbourne: Urban Animal Management Coalition.

12. Ostanello F., Gherardi A., LaPlaca L., Passini A., Prosperi S. (2005) Incidence of injuries caused by dogs and cats treated in emergency departments in a major Italian city. Emergency Medicine Journal. 22: 260-262.

13. Ozanne-Smith J., Ashby K., Stathakis V.Z. (2001) Injury Prevention. 7: 321-326.

14. Parrish H.M., Clack F.B., Brobst D., Mock J.F. (1959) Epidemiology of dog bites. Public Health Reports. 74: 891-903.

15. Patrick G.R., O’Rourke K.M. (1998) Dog and cat bites: epidemiologic analysis suggest different prevention strategies. Public Health Reports. 113: 252-257.

16. Presutti R.G. (2001) Prevention and treatment of dog bites. Am. Fam. Physician. 63: 1567-72.

17. Rosenberg N., Dos Santos L., Abramo T., Schunk J. (1995) Dog bites. Pediatric Emergency Care. 11: 313-316. 
18. Rufino Gonzales J.F. (1990) Prevenir las mordeduras caninas. Rev Enferm. 13: 15-21.

19. Sacks J.J., Kresnow M., Houston B. (1996) Dog bites: how big a problem? Injury Prevention. 2: $52-54$.

20. Sacks J.J., Sinclair L., Gilchrist J., Golab G.C., Lockwood R. (2000) Breeds of dogs involved in fatal human attacks in the United States between 1979 and 1998. JAVMA. 217(6): 836-840.

21. Schalamon J., Ainoedhofer H., Singer G., Petnehazy Th., Mayr J., Kiss K., Höllwarth M.E. (2006) Analysis of dog bites in children who are younger than 17 years. Pediatrics. 117(3): 374-379.

22. Szpakowski N.M., Bonnett B.N., Martin S.W. (1989) An epidemiological investigation into the reported incidents of dog biting in the city of Guelph. Canadian Veterinary Journal. 30: 937-942.

23. Vučinić M., Dordevic M., Radenković B., Janković L., Mirilović M. (2008) Bites to humans caused by stray and owned dogs in Belgrade. Acta Veterinaria (Beograd). 58 (5-6): 563-571.

24. Weiss H.B., Friedman D.I., Coben J.H. (1998) Incidence of dog bites injuries treated in Emergency Departments. The Journal of the American Medical Association. 279 (1): 51-53.

\title{
Biting Humans by Dogs (General Description)
}

\author{
Marat T. Makenov and Olga A. Mihaylova ${ }^{\mathrm{b}}$ \\ ${ }^{a}$ Omsk Research Institute for Natural and Focal Infections, \\ 7 Mira av., Omsk, 644080 Russia \\ ${ }^{b}$ Omsk Regional Center for Hygiene and Epidemiology \\ of Federal Service on Customers' Rights Protection \\ and Human Well - Being Surveillance, \\ 42 a 27 Severnaya st., Omsk, 644116 Russia
}

The analysis of appeals for medical help concerned with dog bites made by dwellers of the Omsk City in 2006-2010 has been performed, using the materials of the "Omsk Regional Center for Hygiene and Epidemiology". In total, 11849 cases of human biting by dogs were registered in this period of time. The mean number of cases is 2901,3 bites per year that is equal to 256,9 cases per 100000 individuals. In opinion of the dogs' victims, $99 \%$ of bites were made by owned dogs, in $66 \%$ humans were bitten by animals familiar to them. The percentage of bites by stray dogs is only 0,36\%. Seasonal relationship has been found: the maximum amount of appeals for medical help is registered in summer months (May-August). The minimum amount is observed in the winter period, from November to February. Children suffer from dog bites more frequently than adults. The percentages of bites in the head and neck regions are relatively high (19-44\%). Adults are most often bitten in arms or legs $(87 \%$ of all registered bites). Females are rarely bitten than males (217,6 and 304,0 bites per 100000 individuals, respectively).

Keywords: dogs, bites, aggression, stray animals. 